\title{
Tec1 Transkripsiyon Faktörünün NTH1 Gen Ekspresyonuna Etkisi
}

\author{
Tülay TURGUT GENÇ*1'D, Selen ÇAKAS ${ }^{2}$ \\ ${ }^{1}$ Çanakkale Onsekiz Mart Üniversitesi, Fen Edebiyat Fakültesi, Biyoloji Bölümü, 17100 Çanakkale \\ ${ }^{2}$ Çanakkale Onsekiz Mart Üniversitesi, Fen Bilimleri Enstitüsü, 17100 Çanakkale
}

Geliş / Received: 06/.09/2018, Kabul / Accepted: 13/05/2019

\begin{abstract}
$\ddot{\mathbf{O z}}$
Hücre içi trehaloz birikimi maya hücrelerinin farklı çevresel streslere karşı oluşturduğu fizyolojik cevaplardan birisidir. Saccharomyces cerevisiae maya hücrelerinde trehaloz miktarı hücre döngüsünün farklı aşamalarında farklı miktarlarda bulunmakta olup kronolojik yaşam uzunluğunu etkilemektedir. Stres koşullarında biriktirilen trehalozun yıkımından sorumlu nötral trehalaz enzimini kodlayan NTH1 geninin ekspresyonu farklı sinyal yolakları üzerinden kontrol edilmektedir. Bu yolaklardan bir tanesi TOR sinyal yolağı olup aynı zamanda bu yolak maya hücrelerinin kronolojik yaşam uzunluğunu etkileyen Tec 1 transkripsiyon faktörünün de stabilitesini etkilemektedir. Trehaloz sentezinden ve yıkımından sorumlu genlerin promotor bölgelerinin analizinde NTH1 promotorundan tespit edilen TCS elementleri Tec1 proteinin NTH1 geninin regülasyonunda görev alma olsılığını kuvvetlendirmektedir. Tec1 transkripsiyon faktörünün NTH1 gen ekspresyonuna etkisini belirlemek amaciyla, yaban tip ve $\Delta t e c 1 S$. cerevisiae maya hücrelerine $N T H 1$ promotor bölgesi ve LacZ gen füzyonu içeren plazmit aktarılmıştır. Kuvvetli azot ve zayıf azot kaynaklarında, Tec1 proteinin varlığında ve yokluğunda maya hücrelerinin trahaloz birikimleri ve $N T H 1$ gen ekspresyon miktarları enzimatik olarak belirlenmiştir. Tec 1 proteininin yokluğunda $N T H 1$ geninin aktive olduğu ve trehaloz birikiminin oldukça azaldığı belirlenmiştir. Elde edilen sonuçlar Tec1 transkripsiyon faktörünün özellikle normal üreme koşullarında NTH1 transkripsiyonunun negatif düzenlenmesi için gerekli olduğunu göstermiştir.
\end{abstract}

Anahtar Kelimeler: NTH1, Tec1p, trehaloz, Saccharomyces cerevisiae

\section{The Effect of Tec1 Transcription Factor on NTH1 Gene Expression}

\begin{abstract}
The intracellular accumulation of trehalose is one of the physiological response of yeast cells to different environmental stresses. The amount of trehalose in the cell changes during the phases of cell cycle and affects the chronological life span of Saccharomyces cerevisiae yeast cells. The expression of the NTH1 gene, which encodes the neutral trehalase enzyme responsible from the stress-accumulated trehalose breakdown, is controlled through different signaling pathways. TOR signaling system, one of these pathways, regulates the stability of Tec1 protein which controls the chronological life span of yeast cells. The detection of TCS elements in NTH1 promotor region enhances the probability of $N T H 1$ gene regulation by Tec1. In order to determine the effect of Tec1 transcription factor on NTH1 gene expression, Nth1-LacZ gene fusion plasmid was transformed to wild type and $\Delta t e c 1$ mutant $S$. cerevisiae yeast cells. The amount of NTH1 gene expression and trehalose accumulation were determined in the presence of good and poor nitrogen sources both in wild type and mutant yeast cells. The results showed that in the absence of Tec1 protein NTH1 gene was activated and trehalose accumulation decreased considerably at normal growth conditions. These results revealed that, Tec1 transcription factor is essential for negative regulation of NTH1 transcription, especially under abundance of nutrient.
\end{abstract}

Keywords: NTH1, Tec1p, trehalose, Saccharomyces cerevisiae

\section{Giriş}

Saccharomyces cerevisiae maya hücrelerinde besin ve feromon bağımlı gerçekleşen hücre bölünmesi ve gelişimi Tec1 transkripsiyon faktörü ile kontrol edilmektedir. Besin açlı̆̆ında Tec1 (Transposon Enhancement Control 1) proteini Ste12 transkripsiyon faktörü ile birlikte pseudohifsel üremeden sorumlu genlerin promotorlarinda bulunan TCS (TEA/ATTS Consensus S equence) 
elementlerine bağlanarak transkripsiyonlarını aktive etmektedir (Madhani ve Fink., 1997). Feromon varlığında ise Tec1-Ste12 dimerik yap1 ayrilır ve Ste12 proteini homodimer oluşturarak 'Mating Type Switch' programının başlaması için gerekli olan genleri aktitleştirerek spor oluşturmaktadır (Bao ve ark., 2004). Besin kisitlamasinın veya feromon üretiminin olmadiğ 1 durumlarda ise Tec1 transkripsiyon faktörü $S$. cerevisiae maya hücrelerinde tomurcuklanarak üreme için gerekli olan genlerin promotorlarına bağlanarak transkripsiyonlarını düzenlemektedir. Maya hücrelerinde gerçekleşen bu morfolojik geçişler Tec1 aracılı MAPK sinyal yolağı ile regüle edilmektedir.

MAPK sinyal yolağı gibi besin miktarına göre regüle edilen TOR sinyal yolağıda hücre dögüsünü ve pseudohifsel-vegetatif üreme geçişlerini kontrol etmektedir (Heitman ve ark., 1991; Barbet ve ark., 1996; Cutler ve ark., 2001). Her iki sinyal yolağıda Tec1 transkripsiyon faktörü aracılığıyla bu olayların koordineli bir şekilde hücrede gerçekleşmesini sağlamaktadır (Brückner ve ark., 2011). TOR sinyal yolağının rapamisin ile inhibisyonu Tec1 proteininde olduğu gibi kronolojik yaşam uzunluğunu (CLS) artırmaktadır (Powers ve ark., 2006; Brückner ve ark., 2011). Düşük azot kaynağı ve rapamisin TOR sinyal yolağını bakılamasına rağmen, Tec1 proteini üzerinde oluşturduğu etki farklıdır. Azot açlığı Tec1 protein stabiltesini artırrırken, rapamisin Tec1 protein stabilitesini azaltmaktadır. Ayrıca TOR sinyal yolağı Tec1 proteininin nükleer lokalizasyonunu etkilememektedir (Brückner ve ark., 2011).

Kalori kısıtlamasına uğrayan maya hücrelerinde hücre içi trehaloz miktarı kronolojik yaşam uzunluğunu değiştirmektedir (Kyryakov ve ark., 2012). S. cerevisiae maya hücrelerinde hücre içi trehaloz miktarı sentez ve yıkımdan sorumlu genlerin sıkı bir şekilde regüle edilmesiyle belirli bir seviyede tutulmaktadır. Trehaloz sentezi Tps1, Tps2, Tps3 ve Ts11 proteinlerinin oluşturduğu TPS (Trehalose Phospahte Synthase) enzim kompleksiyle, yıkımı ise NTH1 geni tarafından kodlanan nötral trehalaz enzimi ile gerçekleşmektedir (Bell ve ark. 1998; Elbein ve ark. 2003). $\mathrm{G}_{0}$ (quiescence) safhasına geçen maya hücrelerinde, Tsl1 proteininin yokluğu trehaloz miktarının düşmesine, protein agregasyonunun azalmasına ve bunlara bağlı olarak kronolojik yaşam süresinin uzamasına neden olmaktadir. Nth1 proteininin yokluğunda ise trehaloz miktarının artması ve buna bağımlı protein agregasyonunun artması kronolojik yaşam süresini kısaltmaktadır (Kyryakov ve ark., 2012).

Tec1 ve Nth1 proteinlerinin kronolojik yaşam süresi üzerine pozitif etkilerinin varlığı (i); ve TOR sinyal sisteminin Tec1 stabilitesini ve NTH1 gen ekspresyonunu regüle etmesi (ii), Tec1 transkripsiyon faktörünün NTH1 gen ekpsresyonunun düzenlenmesinde rolü olduğunu düşündürmektedir. Çalışmaya başlamadan önce TPS kompleksini oluşturan genlerin (TPS1, TPS2, TPS3 ve TSL1) ve NTH1 geninin promotor bölgeleri incelenmiş ve yalnızca $N T H 1$ promotor bölgesinde Tec1 bağlanma dizisinin bulunduğu tespit edilmiştir. $\mathrm{Bu}$ nedenle çalışmada Tec1 transkripisyon faktörünün NTH1 gen ekspresyonuna etkisinin belirlenmesi amaciyla NTH1 promotor bölgesini içeren plazmid yaban tip ve TEC1 mutasyonu taşıyan maya hücrelerine transform edilerek promotor aktivasyonu enzimatik olarak belirlenmiştir. Ayrica yaban tip ve mutant maya hücrelerinin hücre içi trehaloz birikimleri yine enzimatik yöntemle belirlenmiştir. Çalışma sonucunda Tec1 transkripsiyon faktörünün NTH1 gen ekpsresyonunun baskılanmasında görev aldığı ve trehaloz birikimini pozitif yönde etkilediği tespit edilmiştir. Yapılan çalışma ile NTH1 geninin regülasyonunda rolü olan transkripsiyon faktörlerinden bir tanesi daha belirlenerek literatüre katkıda bulunulmuştur. 


\section{Materyal ve Metot}

\subsection{Maya Suşları, Plazmitler ve Üreme Koşulları}

Çalışmada kullanılan BY4741 yaban tip

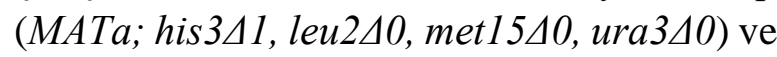

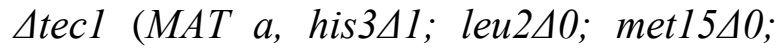
ura340; YBR083w: kanMX4) S. cerevisiae maya suşları EUROSCARF (European Saccahromyces cerevisiae Archive for Functional Analysis) maya koleksiyonundan alınmıştır. Atecl mutant maya suşu BY4741 maya suşu ile izogenik olup TECl gen mutasyonu taşımaktadır. Çalışmada Suc2LacZ ve Nth1-LacZ gen füzyonunu içeren YEp plazmitleri kullanılmıştır. Nth1-LacZ gen füzyonunu içeren plazmitte NTHI promotorunun $-770 \mathrm{bç} \mathrm{uzunluğundaki} \mathrm{bölgesi}$ bulunmakta olup, bu bölge NTH1 geninin ekspresyonu için gerekli kontrol bölgelerini içermektedir (Parrou ve ark., 1997). SUC2 geninin ekspresyonu glikoz ile regüle edildiğinden çalışmamızda Suc2-LacZ gen füzyonu kontrol gen füzyonu olarak kullanılmıştır (Türkel ve ark., 2003).

Plazmit amplifikasyonu için E. coli $\mathrm{MACH} 3 \alpha$ bakteri hücreleri kullanılmıştır. Plazmitlerin bakteri hücrelerine transformasyonu $\mathrm{CaCl}_{2}-$ $\mathrm{MgCl}_{2}$ yöntemi ile seleksiyonu ise ampisilin içeren üreme ortamında gerçekleştirilmiştir (Ausubel ve ark., 1993). Plazmitler saflaştırma kiti (Thermo Scientific; GeneJET Plasmid Miniprep Kit; \#K0502) kullanılarak saflaştırılmış ve $-20{ }^{\circ} \mathrm{C}$ 'de stoklanmıştır. Suc2-LacZ ve Nth1-LacZ gen füzyonunu içeren plazmitlerin BY4741 ve Atecl maya suşlarına transformasyonu lityum asetatpolietilen glikol ( $\mathrm{LiOAc}+\mathrm{PEG}$ ) yöntemi ile yapılmıştır (Rose ve ark., 1990). Transformant maya suşlarının seleksiyonu için urasil içermeyen YNBD-HLM (\%0,16 Yeast Nitrogen Base; \%2 Dextrose; \%0,2 Histidine; \%0,3 Leucine; \%0,2 Methionine; \% 0,5 Ammonium sulfate) kat1 besiyeri kullanılmıştır.
Maya suşlarının ikilenme sürelerini (Doubling Time, Dt) ve spesifik üreme oranlarını (Specific Growth Rate, $\mu$ ) belirlemek için, maya hücreleri \%0,2 Uracil içeren YNBDHLMU siv1 üreme ortamında $30{ }^{\circ} \mathrm{C}$ 'de 125 $\mathrm{rpm} / \mathrm{dk}$ sabit çalkalama ile 48 saat inkübe edilmiştir. $\mathrm{Bu}$ süre boyunca her iki saatte örnek alınarak spektrofotometrede $\mathrm{OD}_{600}$ absorbans değeri ölçülmüş ve bu değerleri ' $\log A$ ' hücre sayıları hesaplanarak zamana karşı grafiği çizilmiştir. Bu grafik kullanılarak logaritmik olarak üreyen hücrelerin bulunduğu zaman aralığına (2-10 saat) karşı ln hücre sayılarının grafiği çizilmiştir. $\mathrm{Bu}$ grafikten ise maya suşlarının ikilenme süreleri ve spesifik büyüme oranları hesaplanmıştır. Ölçümler üç kez tekraralanarak ve standart sapma değerlerinin \%10'dan daha düşük olduğu belirlenmiştir.

Transformant maya hücrelerinin YNBDHLM sivı besiyerinde üretilen gecelik kültürlerinden taze besiyerine $\mathrm{OD}_{600}$ değeri 0,2-0,3 gelecek şekilde hücreler aktarılmış ve $\mathrm{OD}_{600}$ değeri $\sim 0,8-1,0$ olana kadar $30{ }^{\circ} \mathrm{C}$ 'de $125 \mathrm{rpm} / \mathrm{dk}$ sabit çalkalama ile inkübe edilmiştir. Eksponensiyel aşamadaki hücre kültürü iki eşit kısma bölünerek birinci kısımdaki hücreler stres öncesi betagalaktozidaz enzim aktivitesi ve trehaloz miktarının belirlenmesinde kullanılmıştır. Diğer kısımdaki hücreler çöktürülerek yıkanmış ve $0,1 \%$ prolin içeren YN-HLM sıvı besiyerine aktarılmıştır. Azot açlığına maruz bırakılan hücreler 4 saat $30{ }^{\circ} \mathrm{C}$ 'de sabit çalkalama ile inkübe edilmiştir. $\mathrm{Bu}$ süre sonunda hücreler $\beta$-galaktozidaz enzim aktivitesinin ve hücre içi trehaloz miktarının belirlenmesi için çöktürülmüştür. Tüm deneyler üçlü setler olarak yapılmış en az üç kez tekrarlanmış ve standart sapmaları hesaplanmıştır.

\subsection{Enzim Aktiviteleri}

Farklı üreme koşullarında üretilen transformant maya hücrelerinin beta 
galaktozidaz enzim aktivitesi daha önce rapor edildiği gibi yapılmıştır (Guarente ve Ptashe, 1981). Breaking buffer içinde ressupend edilen maya hücrelerinin üzerine $20 \mu \mathrm{l} \% 0,1$ SDS ve $20 \mu \mathrm{l}$ Kloroform eklenerek hücre lizatları hazırlanmıştır. $30 \mu 1$ hücre lizatı 970 $\mu \mathrm{l}$ Z-Buffer üzerine eklenerek reaksiyonun başlaması için $200 \mu \mathrm{l}$ ONPG substratı eklenmiş ve zaman kaydedilmiştir. Sarı renk oluşumu ile birlikte, $0,5 \mathrm{ml} 1 \mathrm{M} \mathrm{Na} \mathrm{NO}_{3}$ eklenerek enzimatik reaksiyonunun durdurulma süresi kaydedilmiştir. Hücreler çöktürülerek süpernatantın spektrofotometrede $\mathrm{OD}_{420}$ absorbans değeri kaydedilmiştir. Transformant maya hücrelerindeki toplam protein miktarı $100 \mu 1$ Folin çözeltisi (Folin Ciocalteu's Phenol Reagent) kullanılarak daha önce anlatıldığ 1 gibi Lowry metodu ile belirlenmiştir (Lowry ve ark., 1951). $\beta$-galaktozidaz aktiviteleri ünite cinsinden hesaplanmış ve bir ünite enzim dakikada hidroliz edilen nmol $\mathrm{ONPG} / \mathrm{mg}$ toplam protein olarak verilmiştir.

Yaban tip ve mutant maya suşlarının trehaloz birikimleri 20-40 mg yaş maya hücresi kullanılarak belirlenmiştir. Hücre pelletinin üzerine $250 \mu \mathrm{l} 0,25 \mathrm{M} \mathrm{Na} \mathrm{CO}_{3}$ eklenerek 2 saat kaynatılmıştır. $\mathrm{Bu}$ süre sonunda hücre lizatlarının üzerine $150 \mu 1 \mathrm{M}$ Asetik Asit ve $600 \mu \mathrm{l} \quad 0,2 \mathrm{M}$ NaOAc eklenerek hafifçe karıştırılmıştır. Daha sonra hücre lizatı üzerine $3 \mathrm{mU}$ Trehalaz enzimi (Sigma T-8778) eklenerek $37{ }^{\circ} \mathrm{C}$ 'de 18 saat süre ile inkübasyona bırakılmıştır (Parrou ve François, 1997). Bu süre sonunda hücreler çöktürülmüş ve trehalaz enziminin trehalozu parçalamasıyla ortaya çıkan glikoz miktarı GOD-POD (Glikoz Oksidaz-Peroksidaz) yöntemi kullanılarak belirlenmiştir (Goldstein ve Lampen, 1975). GOD-POD rekasiyonu sonucunda oluşan rengin OD546 absorbans değeri spektrofotometrik olarak ölçülmüştür. Lizatlarda bulunan glikoz miktarları glikoz standart çözeltisinin içerdiği glikoz miktarına göre hücrenin yaş ağırlığ 1 üzerinden normalize edilerek miligram hücrede biriktirilen mikrogram glikoz olarak $(\mu \mathrm{g}$ glikoz/mg hücre yaş ağırlığg) hesaplanmıştır. Tüm enzimatik deneyler ikili ve üçlü setler olarak en az üç kez tekraralanmış ve standart sapmaları belirlenmiştir.

\section{Bulgular}

Çalışmada kullanılan yaban tip ve $\Delta t e c 1$ mutant maya suşları urasil içeren minimal üreme ortamında ikilenme süreleri ve spesifik büyüme oranları hesaplanmıştır. Yaban tip maya suşunun ikilenme süresi 2 saat 26 dakika ve spesifik büyüme oranı 0,2848 olarak, Atecl mutant maya suşunun ikilenme süresi 2 saat 42 dakika ve spesifik büyüme oranı 0,2564 olarak belirlenmiştir. Yaban tip maya suşu hücre döngüsünü yaklaşık olarak 2,5 saatte tamamlarken $\Delta t e c 1$ mutant maya suşunun hücre döngüsünü yaklaşık olarak 3 saatte tamamladığ1 tespit edilmiştir. Üreme koşullarında ki değişikliğin hücreler üzerindeki metabolik ve genetik etkisini belirleyebilmek için, en az bir hücre döngüsünü tamamlaması gerekmektedir. $\mathrm{Bu}$ nedenle sonraki basamakta gerçekleştirilen inkübasyon süreleri yaban tip ve mutant maya suşu için 4 saat olarak kullanılmıştır.

\subsection{Tec1 proteininin NTH1 gen ekspresyonuna etkisi}

Nth1-LacZ ve Suc2-LacZ gen füzyonu içeren plazmitlerin yaban tip ve $\Delta t e c 1$ mutant maya suşlarına transformasyonları yapılarak logartitmik aşamaya kadar üretilmiş, gen ekspresyon seviyeleri ve trehaloz birikimleri enzimatik olarak belirlenmiştir. Yaban tip maya hücrelerinde $\beta$-galaktozidaz enzim aktivitesi 76,8 8,8 Ünite, $\Delta$ tec 1 mutant maya hücrelerinde ise $551,6 \pm 10,1$ Ünite olarak hesaplanmıştır (Tablo 1). Atecl mutant maya hücrelerinde $\mathrm{NTHI}$ ekspresyonunun yaban tip maya suşundan yaklaşık 7 kat daha fazla olduğu gözlenmiştir. Tec1p yokluğunda NTH1 transkripsiyonunun artmas1 Tec1 proteininin NTH1 geninin bask1lanmasinda görev aldığını göstermektedir. 
S. cerevisiae maya hücreleri için glutamin, glutamat, asparajin ve amonyum kuvvetli ve tercih edilen azot kaynakları iken, prolin ve üre zayıf ve tercih edilmeyen azot kaynaklarıdır. Maya hücreleri üreme ortamlarında kuvvetli azot kaynağının varlığında diğer zayıf azot kaynaklarının kullanımı ile ilgili genlerin ekspresyonunu azot katabolit represyon (Nitrogen Catabolite Repression; NCR) mekanizmasiyla baskılamaktadır (ter Schure ve ark., 2000; Magasanik ve Kaiser, 2002). Azotun miktarı ve kalitesi hücre içi trehaloz birikimini etkilemektedir (Parrou ve ark., 1999). Bu nedenle çalışmamızda kuvvetli azot kaynağında üretilen maya hücreleri zayıf azot kaynağı içeren ortama aktarılarak bir hücre döngüsü tamamlamaları sağlanmış ve daha sonra hücrelerde ki NTH1 transkripsiyon miktarı ve hücre içi trehaloz birikimi enzimatik olarak belirlenmiştir. Yaban tip maya hücreleri prolin içeren zayıf azot kaynağına geçirildiklerinde $\beta$-galaktozidaz enzim aktivitesinin yaklaşık 8 kat $\Delta$ tec 1 mutant maya hücrelerinde ise 2 kat arttı̆̆ 1 belirlenmiştir (Tablo 1). Tec1 proteininin yokluğunda NTH1 gen ekspresyonunun yeterince aktive edilemediği yaban tip maya hücresinden 4 kat daha düşük olduğu tespit edilmiştir.

SUC2 geni glikoz represyon-derepresyon mekanizması ile regüle edilmektedir (Neigeborn ve Carlson, 1984). Çalışmada kullanılan üreme ortamı glikoz içerdiğinden SUC2 geni baskılanmış olup stress koşullarında aktive olamamaktadır. $\mathrm{Bu}$ ndenele SUC2 gen ekspresyonu stress ile aktive edilemediğinden dolayı çalışmada kontrol gen füzyonu olarak kullanılmıştır. Suc2-LacZ transkripsiyon seviyesi kuvvetli azot kaynağında yaban tip maya suşunda $1,5 \pm 0,02$ ünite, $\Delta t e c 1$ maya suşunda $0,5 \pm 0,01$ ünite olarak ölçülürken zayıf azot kaynağı içeren ortamda yaban tip maya suşunda $0,1 \pm 0,01$ ünite, $\Delta t e c 1$ maya suşunda $0,1 \pm 00,1$ ünite olarak ölçülmüsstür. Beklendiği gibi
SUC2 gen ekspresyonun glikoz içeren ortamda, azot kaynağının kalitesine ve miktarına bağlı olmaksızın, düşük seviyededir. $\mathrm{Bu}$ durum Nth1-LacZ ölçümlerinin doğruluğunu teyit etmektedir.

Tablo 1. Tec1 proteininin NTHI gen ekspresyonuna etkisi

\begin{tabular}{ccc}
\hline \multirow{2}{*}{$\begin{array}{c}\text { Azot } \\
\text { Kaynağ1 }\end{array}$} & \multicolumn{2}{c}{$\beta$-Galaktozidaz Aktivitesi* } \\
\cline { 2 - 3 } & Yaban tip & Atec1 \\
\hline$\left(\mathrm{NH}_{4}\right)_{2} \mathrm{SO}_{4}$ & $76,8 \pm 8,6$ & $551,6 \pm 20,1$ \\
Proline & $626,0 \pm 14,6$ & $1177,7 \pm 42$ \\
\hline & & \\
\hline nmol ONPG/dak/mg protein &
\end{tabular}

\subsection{Tec1 proteininin trehaloz birikimine etkisi}

Trehaloz, S. cerevisiae tarafindan normal üreme koşullarında durağan aşamada, stres koşullarında ise üreme fazından bağımsız olarak biriktirilerek stres koşulları sona erdiğinde yıkılarak enerji kaynağı olarak kullanılmaktadır. Tec1 proteininin trehaloz birikimine etkisini belirleyebilmek için, logaritmik olarak üreyen maya hücrelerinin içerdiği trehaloz miktarı enzimatik olarak belirlenerek Tablo 2'de verilmiştir. Yaban tip maya hücrelerinde ölçülen trehaloz miktarının $\Delta t e c 1$ mutant maya hücrelerinde ölçülen trehaloz miktarından yaklaşık 10 kat fazla olduğu belirlenmiştir. NTH1 gen ekspresyonunun $\Delta t e c 1$ mutant maya hücrelerinde yüksek olmasından dolayı trehaloz birikiminin azalmasına neden olmuş olabilir.

Tablo 2. Tec1 proteininin trehaloz birikimine etkisi

\begin{tabular}{ccc}
\hline Azot & \multicolumn{2}{c}{ Trehaloz Miktar1* } \\
\cline { 2 - 3 } Kaynağ 1 & Yaban tip & $\Delta t e c 1$ \\
\hline$\left(\mathrm{NH}_{4}\right)_{2} \mathrm{SO}_{4}$ & $277,4 \pm 36,8$ & $27,2 \pm 6,0$ \\
Proline & $656,1 \pm 26,6$ & $802,2 \pm 37$
\end{tabular}

* $\mu \mathrm{g}$ glikoz/mg hücre yaş ağırlığı 
Kuvvetli azot kaynağında üretilen maya hücreleri zayıf azot kaynağı içeren ortama geçirildiklerinde, trehaloz miktarının yaban tip maya hücrelerinde 2 kat, mutant maya hücrelerinde ise $30 \mathrm{~kat}$ arttığ 1 tespit edilmiştir (Tablo 2). Normal koşullarda yaban tip maya hücrelerinde gözlenen trehaloz birikimi mutant hücrelerden 10 kat fazla iken, stres koşullarında trehaloz birikiminin mutant hücrelerle yaklaşık aynı seviyede kaldığı gözlenmiştir.

\section{Sonuc}

Tec1 proteini, promotor bölgesinde TEA/ATTS elementlerine sahip genlere bağlanarak, ekspresyonlarını düzenlemektedir. TOR sinyal yolağı, besin çeşitine ve miktarına bağlı olarak Tec1 proteininin aktivitesini kontrol etmektedir. Zayıf azot kaynağı TOR sinyal yolağını bakılamasına rağmen Tec1 proteininin stabilitesini artırmaktadır. NTH1 gen ekspresyonu ağırlıklı olarak TOR sinyal sistemi üzerinden regüle edilmektedir. NTH1 promotor bölgesinde Tec1 transkripsiyon faktörünün bağlandığı TEA/ATTS elementleri bulunmaktadır. Normal üreme koşullarında NTH1 transkripsiyonu bazal seviyede gerçekleşmesine rağmen $\Delta t e c 1$ maya hücrelerinde NTH1 gen ekspresyonu aktive olmaktadır. $\mathrm{Bu}$ durum Tecl transkripsiyon faktörünün NTH1 transkripsiyonunu negatif olarak regüle ettiğini göstermektedir.

Prolinin varlığı maya hücrelerinde düşük azot sinyali oluşturarak TOR sinyal sisteminin Rapamisin benzeri baskılanmasina neden olmaktadir. TOR sinyal sisteminin baskilanmas1 ile Msn2p/Msn4p transkripsiyon faktörlerinin nükleusa geçmesi ve NTH1 promotoruna bağlanarak transkripsiyonun aktivasyonu gerçekleşmektedir (Beck ve Hall, 1999). Ancak TOR sisteminin baskılanması Tec1 proteininin stabilitesini düşürmektedir. $\mathrm{Bu}$ nedenle normal üreme koşullarında yaban tip maya hücrelerinde Tec1 proteininin stabilitesi yüksek olduğu için NTH1 transkripsiyonu baskılanmakta; zayıf azot kaynağında ise Tec1 proteininin stabilitesi azaldı $\breve{g}_{1}$ için NTH1 transkripsiyon miktarı $\Delta t e c 1$ mutant maya hücrelerinde gözlenen seviyede olmaktadır. $\mathrm{Bu}$ durum Tec1 transkripsiyon faktörünün NTH1 transkripsiyonunu stres koşullarından ziyade ağırlıklı olarak normal üreme koşullarında regüle ettiğini göstermektedir.

Trehalaz enzimi sentezlendiğinde inaktif olarak sitoplazmada bulunur ve PKA aracilı fosforilasyon ile aktif hale geçirilmektedir (Schepers ve ark., 2012). NTH1 ekspresyonunda ki artışın direk olarak trehaloz birikiminde gözlenen düşüş ile ilişskilendirmek doğru olmamaktadır. Tec1 transkripsiyon faktörünün trehaloz sentezinden sorumlu genlerinde regülasyonunda rolünün olması kuvvetle muhtemeldir. $\mathrm{Bu}$ yüzden $\Delta t e c 1$ mutant maya hücrelerinde TPS1 gen ekspresyonunun belirlenmesi uygun olacaktır.

\section{Kaynaklar}

Ausubel, F.M., Brent, R., Kingston, R.E., Moore, D.D., Seidman, J.G., Smith, J.A., Struhl, K. 1993. "Current Protocols in Molecular Biology". Greene Publishing Association/Wiley Interscience, New York.

Bao, M.Z., Schwartz, M.A., Cantin, G.T., Yates, J.R., Mdhani, H.D. 2004. "PheromoneDependent Destruction of the Tec1 Transcription Factor is Required for MAP Kinase Signaling Specificity in Yeast", Cell, 119(7), 991-1000.

Barbet, N.C., Schneider, U., Helliwell, S.B., Stansfield, I., Tuite, M.F., Hall, M.N. 1996. "TOR Controls Translation Initiation and Early G1 Progression in Yeast", Molecular Biology of Cell, 7, 25-42.

Beck, T., Hall, M.N. 1999. "The TOR signalling pathway controls nuclear localization of nutrient-regulated transcription factors", Nature, 402, 689-692. 16. 
Bell, W., Sun, W., Hohmann, S., Wera, S., Reinders, A., De Virgilio, C., Wiemken, A., Thevelein, J.M. 1998. "Composition and Functional Analysis of the Saccharomyces cerevisiae Trehalose Synthase Complex", Journal of Biological Chemistry, 273(50), 33311-33319.

Brückner, S., Kern, S., Birke, R., Saugar, I., Ulrich, H.D., Mösch, H.U., 2011. "The TEA Transcription Factor Tec1 Links TOR and MAPK Pathways to Coordinate Yeast Development", Genetics, 189(2), 479-494.

Cutler, N.S., Pan, X. Heitman, J., Cardenas, M. E. 2001. "The TOR Signal Transduction Cascade Controls Cellular Differentiation in Response to Nutrients", Molecular Biology of Cell, 12, 4103-4113.

Elbein, A.D., Pan, Y.T., Pastuszak, I., Carroll, D. 2003. "New Insights on Trehalose: a Multifunctional Molecule", Glycobiology, 13(4),17R-27.

François, J, Parrou, J.L. 2001. Reserve carbohydrates metabolism in the yeast Saccharomyces cerevisiae. FEMS Microbiol Rev., 25(1):125-45.

Goldstein, A., Lampen, J.O., 1975. "Beta-DFructofuranoside Fructohydrolase from Yeast", Methods in Enzymology, 42, 504- 511.

Guarente, L., Ptashne, M., 1981. "Fusion of Escherichia coli lacZ to the Cytochrome c Gene of Saccharomyces cerevisiae", Proceedings of the National Academy of Sciences, 78, 2199-2203.

Heitman, J., Movva, N.R., Hall, M.N. 1991 "Targets for Cell Cycle Arrest by the Immunosuppressant Rapamycin in Yeast", Science, 253, 905-909.

Kyryakov, P., Beach, A., Richard, V.R., Burstein, M.T., Leonov, A., Levy, S., Titorenko, V.I. 2012. "Caloric Restriction Extends Yeast Chronological Lifespan by Altering a Pattern of Age-related Changes in
Trehalose Concentration", Frontiers in Physiology, 3, 256.

Lowry, O.H., Rosenbrough, N.J., Farr, A.L., Randall, R.J. 1951. "Protein Measurement with the Folin Phenol Reagent", Journal of Biological Chemistry, 193, 265-275.

Madhani, H.D., Fink, G.R. 1997. "Combinatorial Control Required for the Specificity of Yeast MAPK Signaling”, Science, 275(5304), 1314-1317.

Magasanik, B., Kaiser, C.A. 2002. "Nitrogen Regulation in Saccharomyces cerevisiae", Gene, 290(1-2), 1-18.

Neigeborn, L, Carlson, M. 1984. "Genes affecting the regulation of SUC2 gene expression by glucose repression in Saccharomyces cerevisiae", Genetics, 108(4),845-858.

Parrou, J.L., François, J. 1997. “A Simplified Procedure for an Rapid and Reliable Assay of Both Glycogen and Trehalose in Whole Yeast Cells", Analytical Biochemistry, 248, 186188.

Powers, R.W.3rd., Kaeberlein, M., Caldwell, S.D, Kennedy, B.K., Fields, S. 2006 "Extension of Chronological Life Span in Yeast by Decreased TOR Pathway Signaling", Genes and Development, 20,174184.

Rose ,M.D., Winston, F., Heiter, P. 1990. "Methods in Yeast Genetics". A Laboratory Course Manual, Cold Spring Harbor Laboratory Press Books.

Schepers, W., Zebroeck, G.V., Pinkse, M., Verhaert, P., Thevelein, J.M. 2012. "In Vivo Phosphorylation of Ser21 and Ser83 during Nutrient-induced Activation of the Yeast Protein Kinase A (PKA) Target Trehalase", The Journal of Biological Chemistry, 287 (53), 44130-44142.

Ter Schure, E.G., Van Riel, N.A., Verrips, C.T. 2000. "The Role of Ammonia 
Metabolism in Nitrogen Catabolite

Repression in Saccharomyces cerevisiae", FEMS Microbiology Reviews, 24: 67-83.

Türkel, S, Turgut, T, López, M.C., Uemura, H., Baker, H.V. 2003. "Mutations in GCRl affect SUC2 gene expression in Saccharomyces cerevisiae", Molecular Genetics and Genomics, 268(6),825-831. 